\title{
Case Report: Echocardiography in Fallot Tetralogy
}

\author{
Matías Olózaga ${ }^{1}$, Paula Manso ${ }^{2}$, Julia Peña ${ }^{2}$ and Enrique Mendano ${ }^{3}$ \\ ${ }^{1}$ Pediatric cardiovascular anesthesiologist, Master in echocardiography, Hospital el Cruce, Florencio Varela, Argentina \\ ${ }^{2}$ Cardiologists Hospital el Cruce, Florencio Varela, Argentina \\ ${ }^{3}$ Pediatric cardiovascular surgeon, Hospital el Cruce Florencio Varela, Argentina
}

Submission: December 09, 2019; Published: January 07, 2020

*Corresponding author: Matías Olózaga, Pediatric cardiovascular anesthesiologist, Master in echocardiography, Hospital el Cruce, Florencio Varela, Buenos Aires province, Argentina

Summary

The tetralogy of fallot is the most frequent cyanotic congenital heart disease. It presents a clinical case of a pediatric patient who was monitored with transesophageal echocardiography and shows the images and changes in handling due to the echocardiographic monitoring.

Keywords: Tetralogy of fallot; Anesthesia; Echocardiography

\section{Case Report}

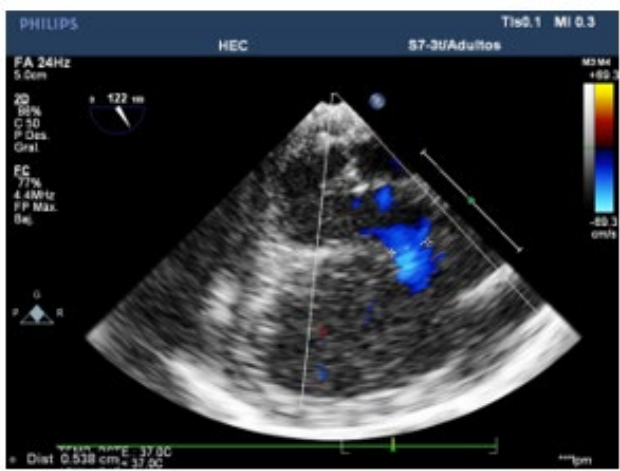

Figure 1: VSD and aortic overriding the ventricular septum.

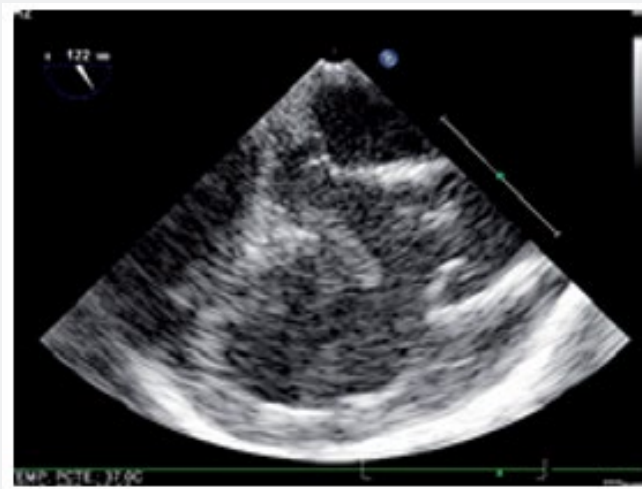

Figure 2: Narrowing of the right ventricular outflow tract (RVOT).
We present a five years old boy and six kg of weight, with diagosis of tetralogy of fallot. He was born from term and he doesn't present any other congenital anomalies. He is under propanolol treatment due to hypoxia and cyanosis crisis. Having reaches an adequate weight, it is decidedto have surgery to repair his cardiac pathology. At his arrival in the operating room, non invasive monitoring is installed, then anesthesia inhalated induction with Sevoflurane 8\% plus oxygen 100\%. 2 pheripherial venous cathethers $22 \mathrm{~g}$ were placed. $3 \mathrm{mg}$ of Rocuronium and 40 micrograms of fentanyl were given. It is intubated with and orotracheal tube $\mathrm{N}^{\circ} 4$ without ballon. Anesthesia is maintained with sevoflurane $1.5 \%$, remifentanyl $0.5 \mathrm{mcg} / \mathrm{kg} / \mathrm{min}$ and relaxing (rocuronium) as needed. It is placed right femoral artery cathether for invasive blood pressure monitoring and left anterior jugular venous cathether (4Fr-2 lumens) with ultrasound guide. The pediatric multiplanar Philips ETE probe is placed and the images are obtained from of the $15 \mathrm{~cm}$ of the dental arch. The diagnosis of Tetralogy of Fallot is confirmed: a $6 \mathrm{~mm}$ ventricular septal defect (VSD) is observed, aortic valve overriding the ventricular septum (Figure 1), narrowing of the right ventricular (RV) outflow tract (RVOT) (Figure 2) with a gradient of $67 \mathrm{mmHg}$ (Figure 3) and a left ventricular ejection fraction (LVEF) of $65 \%$. In additin, the bad function of right ventricle with a TAPSE (tricuspid annular plane systolic excursión) below the normal values (>14mm) (Figure 4). The patient is admitted to extracorporeal circulation, guiding fluid therapy under echocardiography and it is not necessary to add vasoactive drugs. It is performed a closure of the VSD by means of a right auriculotomy verifying a $29 \mathrm{mmHg}$ gradient, indicating 
the presence of a small residual VSD (Figure 5). At the exit of the cardiopulmonary bypass machine (CPB), adrenaline $0.02 \mathrm{mcg} /$ $\mathrm{kg}$ min -1 and milrinone $0.5 \mathrm{mcg} / \mathrm{kg} / \mathrm{min}$ are used, in a planned way due to the images of the bad function of the RV displayed on echocardiography. The RVOT infundibulum was also taked through the pulmonary artery, being considered the procedure as successful since the gradient in the TSVD decreased to $11 \mathrm{mmHg}$ (Figure 6). Because the RV function reflected by TAPSE did not have a clear improvement in the Post CPB echocardiography it was decided to add milrinone (Figure 7). Finally, the success of the surgery is verified with an adequate ejection fraction (EF) (Figure 8).

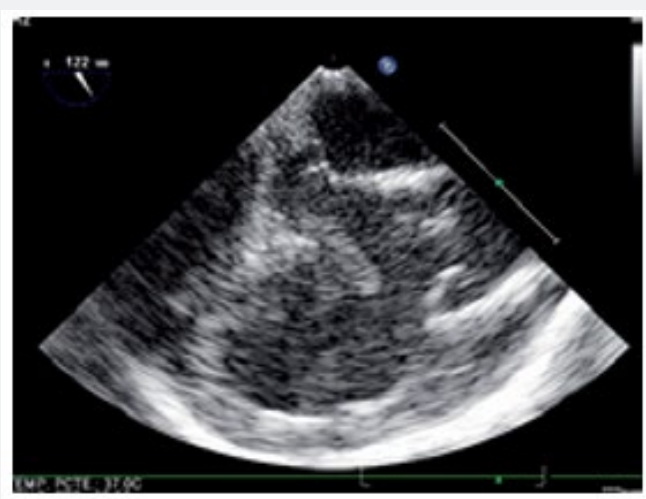

Figure 2: Narrowing of the right ventricular outflow tract (RVOT).

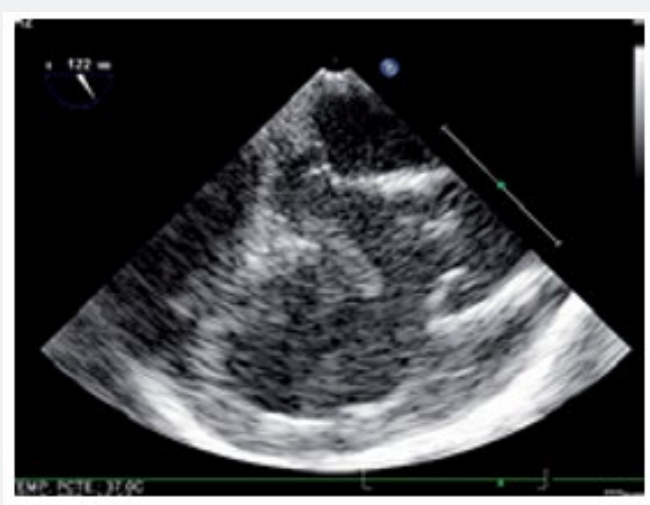

Figure 3: It is shown a RVOT gradient of $67 \mathrm{mmHg}$.

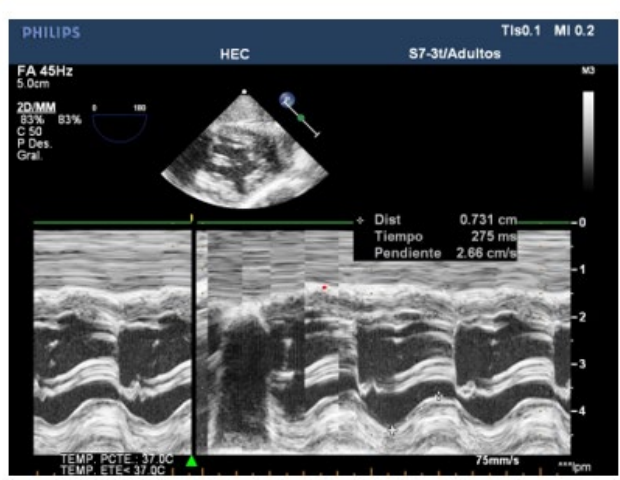

Figure 4: TAPSE: $7 \mathrm{~mm}$.

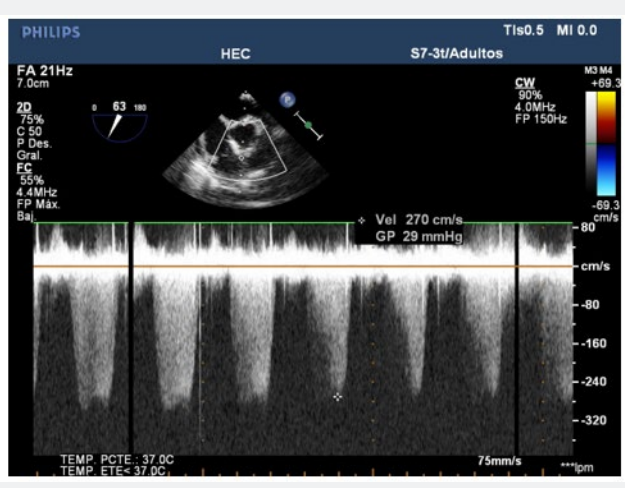

Figure 5: VSD closure: a $29 \mathrm{mmHg}$ gradient is observed, indicating that a small residual CIV remains.

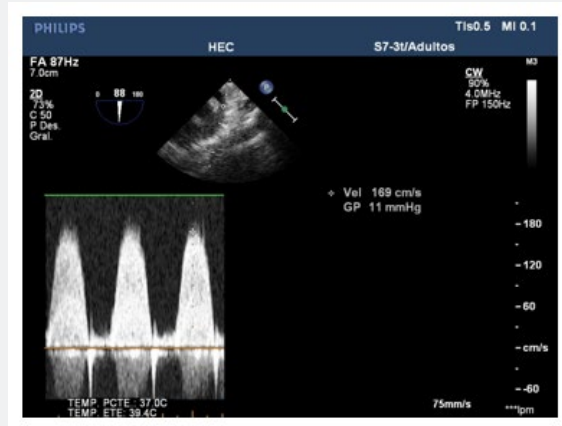

Figure 6: RVOT GRADIENT: $11 \mathrm{mmHg}$.

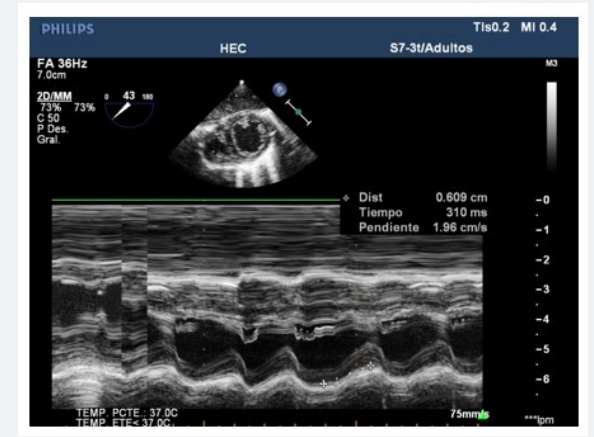

Figure 7: TAPSE: $6 \mathrm{~mm}$.

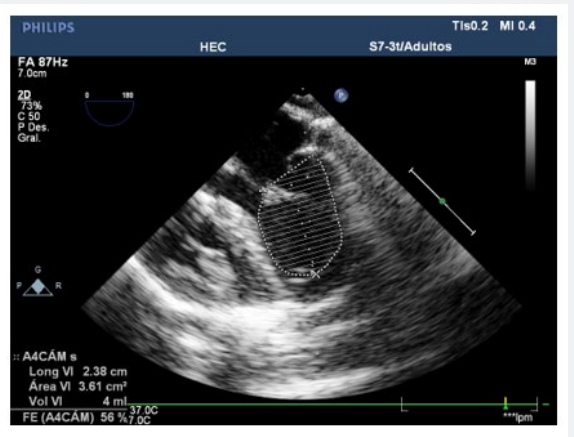

Figure 8: LVEF: 56\%.

\section{Discussion}

The most frequent of congenital cyanotic heart disease is the tetralogy of Fallot that means to be $10 \%$ of congenital heart 
malformations $[1,2]$. The characteristics of this pathology are due to a partial anterior septal movement pulmonary aortium which causes:

Pulmonary stenosis: which can be subvalvular - valvular supravalvular.

VSD: subaortic

Aortic valve overriding ventricular septum: it is because septum IV is deflected forward and right. This causes poor alignment with the anterior wall of the aorta that is connected with both ventricles.

RV hypertrophy: by pulmonary stenosis.

Depending on the degree of displacement of the aorticpulmonary septum, the TOF can be $[3,4]$ :

a) Total: ductus dependent.

b) Minimal: the output of the RV is slightly narrow with small VSD and minimal aortic riding: pink TOF.

c) What marks the degree of severity of TOF is the size of the pulmonary ring and valve and the degree of obstruction of the RVOT [5].

d) Small ring: transannular patch is needed in surgery which would lead to future reoperations.

e) Normal ring: surgery respects the pulmonary valve.

The most favorable for surgical correction and best prognosis is TOF with normal tree lung.

\section{Special tof subgroups:}

a) Small pulmonary branches: in normal RN the pulmonary branches have a diameter $3.5-4 \mathrm{~mm}$. A size $<3 \mathrm{~mm}$ is problematic for surgery $[6,7]$.

b) Disconnection of the branches: one of the branches is born from the ascending aorta.

c) Absence of a pulmonary branch: it is supplied by collateral branches.

d) Pulmonary valve agenesis: part of the valvular tissue is missing due to functionally non-existent. Pulmonary insufficiency is severe and with each beat it expels more blood which dilates the pulmonary artery. It is associated with tracheomalacia or broncomalacia [8].

e) Coronary abnormalities: anterior descending artery birth from right coronary artery, crossing the infundibulum of the RV which makes more difficult the surgical correction of pulmonary stenosis [9].

\section{TOF physiopathology}

The pathophysiology will depend on the degree of obstruction of the RVOT and the size of the VSD and of the Systemic vascular resistance (SVR) and Pulmonary vascular resistance (PVR). There is an obstruction to the flow of blood to the lungs and due to the VSD produces a shunt of desaturated blood from right to left: D-I shunt causing desaturation and cyanosis. The degree of arterial desaturation depends on the amount of desaturated blood derived by the shunt given by the interrelation between the obstruction of the RVOT and the SVR: The more severe the obstruction to the RVOT or the more the SVR decreases, the greater the shunt of blood from the RV to the aorta causing cyanosis. If the PVR decreases, reduces the pressure in the RV which dimishes the D-I shunt. On the other hand if the SVR decreases, increases the D-I shunt causing cyanosis. The symptoms depend on Pulmonary Estenosis $[10,11]$, if it is severe there is cyanosis due to increased D-I shunt by the VSD; if it is not severe increases the I-D shunt by VSD and from there to pulmonary circulation causing pulmonary hyperflow and heart failure. The squatting improves symptoms because the Blood pressure (BP) increases by increasing abdominal pressure which results in an increase in blood pressure which favors the ID shunt for the VSD. Crises of hypoxia and cyanosis occur when the SVR decreases, due to, for example during anesthetic induction or what increases the D-I shunt (cry -adrenergic discharge- RVOT spasm) and this vicious circle is favored [12]. In laboratory tests, polycythemia stands out (Hto 60-70\%, hemostasis abnormalities (thrombocytopenia, platelet dysfunction, hypofibrinogenemia, increased fibrinolysis, coagulation factor deficit) everything that contributes to increase perioperative bleeding.

\section{Anesthetic Management}

A balance must be made between the PVR and the SVR. If the obstruction is minimal, there is I-D Shunt through VSD with pulmonary hyperflow, you should avoid diminishing PVR and increase the SVR. If the obstruction is severe with cyanosis and polycythemia, the SVR should be maintained or increased to minimize the D-I Shunt and abundant fluid therapy. For cyanotic children, is recommended the use of ketamine IM or EV and midazolam orally. In contrast, in less cyanotic children, inhalation induction can be performed. Nitrous oxide is contraindicated, because it increases the PVR in patients with congenital heart diseases. For the treatment of cyanotic crisis, the trigger must be avoided, (pain, anxiety), hyperventilate with 100\% FiO2 to decrease PVR and abundant fluid therapy $(7-10 \mathrm{ml} / \mathrm{kg})$. It is very important to know the acid base state of the patient and if necessary correct acidosis with bicarbonate $(0.5 \mathrm{meq} / \mathrm{kg})$. B-blockers follow a very important role reducing infundibular spasm. (esmolol 100mcg/kg)

\section{Echocardiography in Tetralogy of Fallot $[12,13,14]$}

Echocardiography plays a fundamental role, since in the operating room it will allow the evaluation of VSD before surgery, its location, the degree of aortic riding. It is also important to know the degree of pulmonary stenosis, the state of coronary trunk and pulmonary artery and other associated abnormalities such as the presence of patent foramen ovale that is observed in up to a 
third of patients. The interventriular septum defect must also be carefully evaluated, a $80 \%$ is perimembranous and is generally a large subaortic defect and extends from the non-coronary leaflet and right coronary leaflet of the aortic valve to the inferior membranous septum and with color doppler determine size and direction of the shunt. The anterior and cephalic deviation of the conal septum causes a narrowing of the RVOT, which begins in the crista supraventricularis and extends to the pulmonary valve ring. Depending on the degree of obstruction of the RVOT the symptomatology will be more or les severe, if it is severe there is D-I shunt through VSD and is a cyanotic patient; and if the obstruction is slight, there is an I-D shunt with pulmonary flow and is called Pink Fallot. This is also why it is important to evaluate the pulmonary valve and its ring, which in a high percentage may be hypoplasic In addition the echocardiography allows the evaluation of the anatomy of the coronary arteries since there are $10 \%$ of patients with coronary abnormalities being the most common that is the right coronary artery crossing the RVOT and this makes it difficult to surgery requiring the placement of a tube of the RV to the pulmonary artery.

\section{Conclusion}

In conclusion, intraoperative TEE is essential in the management of a correction of tetralogy of Fallot, since it allows the surgeon to make appropriate decisions and evaluate in the operating room the result of their procedures. For anesthesiologists it has become a fundamental tool for the selection of vasoactive drugs and for complex management of Systemic and Pulonary vascular resistance.

\section{References}

1. Hervias, teigell, peleteiro anesthesia manual for the management of patients with congenital heart diseases. Pediatric cardiology $2^{\text {nd }} e d n$.
2. Mark lewin, karen stout echocardiography in congenital heart disease. Elsevier.

3. Eidem, cetta, o`leary echocardiography in pediatric and adult congenital heart disease.

4. (2012) Tetralogy of fallot: perioperative anesthetic management of children and adults.

5. Soo-jin kim, sin-ae park, jinyoung song, woo sub shin (2013) the role of transesophageal echocardiography during surgery for patients with tetralogy of fallot. Pediatr cardiol 34: 240-244.

6. Mario carminatti, francesca pluchinotta, lucine piazza, angelo micheletti, diana negira (2015) echocardiographic assessment after surgical repair of tetralogy of fallot. Pediatric cardiology 1-9.

7. Pooja swamy, aditya bharadwaj, padmii varadarajan (2014) echocardiographic evaluation of tetralogy of fallot.

8. Amolca (2017) pediatric echocardiography. Liliana lopes chapter 23 tetralogy of fallot.

9. Effect of chronic right ventricular volume overload on ventricular interaction in patients after tetralogy of fallot repair.

10. Andreea dragulescu, mark k. Friedberg, lars grosse-wortmann, andrew redington, luc mertens from the division of cardiology, labatt family heart centre, department of pediatrics, the hospital for sick children, university of toronto, toronto, ontario, canada.

11. The impact of pulmonary regurgitation on right ventricular regional myocardial function: an echocardiographic study in adults after total repair of tetralogy of fallot

12. Ewa kowalik, miroslaw kowalski, jacek r_o_za_nski, mariusz ku_ smierczyk, piotr hoffman, from the department of congenital heart diseases.

13. Regional dysfunction of the right ventricular outflow tract reduces the accuracy of doppler tissue imaging assessment of global right ventricular systolic function in patients with repaired tetralogy of fallot.

14. Laura mercer-rosa, aimee parnell, paul r. Forfia, wei yang, elizabeth goldmuntz, et al. Tricuspid annular plane systolic excursion in the assessment of right ventricular function in children and adolescents after repair of tetralogy of fallot.

Commons Attribution 4.0 License

DOI: 10.19080/JAICM.2020.10.555781

\section{Your next submission with Juniper Publishers will reach you the below assets}

\begin{tabular}{|l|}
\hline \multicolumn{1}{|c|}{ Your next submission with Juniper Publishers } \\
will reach you the below assets \\
- Quality Editorial service \\
- Swift Peer Review \\
- Reprints availability \\
- E-prints Service \\
- Manuscript Podcast for convenient understanding \\
- Global attainment for your research \\
- Manuscript accessibility in different formats \\
( Pdf, E-pub, Full Text, Audio) \\
- Unceasing customer service \\
Track the below URL for one-step submission \\
https://juniperpublishers.com/online-submission.php \\
\hline
\end{tabular}

